\title{
A Cross-Sectional Study Assessing Appropriateness Of Inhaled Corticosteroid Treatment In Primary And Secondary Care Patients With COPD In Sweden
}

This article was published in the following Dove Press journal: International Journal of Chronic Obstructive Pulmonary Disease

\author{
Johanna Sulku $\mathbb{1}^{1,2}$ \\ Christer Janson (iD ${ }^{3}$ \\ Håkan Melhus (iD ${ }^{4}$ \\ Andrei Malinovschi $\mathbb{1}^{5}$ \\ Björn Ställberg $\mathbb{( D}^{6}$ \\ Kristina Bröms $\mathbb{D}^{2,6}$ \\ Marieann Högman (1D ${ }^{3}$ \\ Karin Lisspers $\mathbb{D}^{6}$ \\ Margareta Hammarlund- \\ Udenaes (1D) \\ Elisabet I Nielsen (D) \\ 'Department of Pharmaceutical \\ Biosciences, Uppsala University, Uppsala, \\ Sweden; ${ }^{2}$ Centre for Research and \\ Development, Uppsala University/Region \\ Gävleborg, Gävle, Sweden; ${ }^{3}$ Department \\ of Medical Sciences, Respiratory, Allergy \\ and Sleep Research, Uppsala University, \\ Uppsala, Sweden; ${ }^{4}$ Department of \\ Medical Sciences, Clinical \\ Pharmacogenomics and Osteoporosis, \\ Uppsala University, Uppsala, Sweden; \\ ${ }^{5}$ Department of Medical Sciences, Clinical \\ Physiology, Uppsala University, Uppsala, \\ Sweden; ${ }^{6}$ Department of Public Health \\ and Caring Sciences, Family Medicine and \\ Preventive Medicine, Uppsala University, \\ Uppsala, Sweden
}

Correspondence: Johanna Sulku Department of Pharmaceutical Biosciences, Faculty of Pharmacy, Uppsala University, Box 59I, Uppsala SE-75I 24, Sweden

Tel +46736357075

Fax +4626531237

Email johanna.sulku@farmbio.uu.se
Purpose: Inhaled corticosteroids (ICS) are often more widely prescribed in the treatment of chronic obstructive pulmonary disease (COPD) than what is recommended in the guidelines. The aim of this study was to evaluate the appropriateness of ICS treatment in COPD patients using the algorithm proposed by the International Primary Care Respiratory Group (IPCRG) and to identify factors associated with ICS treatment.

Patients and methods: Appropriateness of ICS therapy was studied with respect to concomitant asthma, history of exacerbations and blood eosinophils (B-Eos) in a Swedish cohort of primary and secondary care patients with COPD. Factors associated with ICS were investigated using multivariable logistic regression.

Results: Triple treatment was found to be the most common treatment combination, used by $46 \%$ of the 561 included patients, and in total $63 \%$ were using ICS. When applying the IPCRG algorithm, there was a possible indication for discontinuation of ICS in $55 \%$ of the patients with ICS treatment. Of the patients not using ICS, 18\% had an indication for starting such treatment. The strongest factors associated with ICS therapy were frequent exacerbations (aOR 8.61, 95\% CI 4.06, 20.67), secondary care contacts (aOR 6.99, 95\% CI 2.48, 25.28) and very severe airflow limitation (aOR 5.91, 95\% CI 1.53, 26.58).

Conclusion: More than half of the COPD patients on ICS met the criteria where withdrawal of the treatment could be tried. There was, however, also a subgroup of patients not using ICS for whom there was an indication for starting ICS treatment. Patients using ICS were characterized by more frequent exacerbations and lower lung function.

Keywords: ICS, pharmacological management, inappropriate therapy, chronic obstructive pulmonary disease, IPCRG

\section{Introduction}

The primary role of inhaled corticosteroid (ICS) treatment in stable chronic obstructive pulmonary disease (COPD) is to prevent and reduce the risk and severity of exacerbations through combination with long-acting beta-2-agonists (LABAs). ${ }^{1}$ However, there is some evidence suggesting that dual bronchodilator therapy with LABAs and longacting muscarinic antagonists (LAMAs) is more effective in preventing exacerbations than ICS in combination with LABAs. ${ }^{2}$ There is also data implying that for some patients with severe COPD who are receiving treatment with ICS in combination with LABA and LAMA (triple treatment) the ICS component of the treatment can be withdrawn without an increase in severe exacerbations. ${ }^{3}$ Triple treatment has also been shown to decrease the risk of exacerbations more effectively compared to a 
treatment with dual bronchodilator therapy. ${ }^{4}$ That said, there are conflicting results of which of the drug combinations give a better exacerbation reduction, dual bronchodilators or ICS in combination with bronchodilators. Further, it is known that COPD patients on ICS-containing therapy have a significantly higher risk for adverse events such as pneumonia. ${ }^{4}$

Previous studies have shown that ICS-containing treatments are more widely prescribed in COPD than what is recommended in the guidelines. ${ }^{5,6}$ Sixty-three percent of the newly diagnosed GOLD A and B category patients were prescribed ICS within 3 months of a COPD diagnosis in a cross-sectional registry-based study in the $\mathrm{UK}^{5}$ and half of the patients in the GOLD A and B categories were prescribed ICS in a cross-sectional study in seven Latin American countries. ${ }^{7}$ In Sweden, the prevalence of triple therapy including ICS has significantly increased from $29 \%$ to $40 \%$ between 2005 and 2014, according to a study of COPD patients from primary and secondary care. ${ }^{6}$

In July 2018, the International Primary Care Respiratory Group (IPCRG) modified an algorithm proposed earlier ${ }^{8}$ for stepping down ICS in patients with COPD. ${ }^{9}$ The aim of the algorithm is to evaluate appropriateness of ICS therapy in COPD in order to help identify patients who would benefit from ICS treatment and patients in whom it might be appropriate to withdraw the ICS. ${ }^{9}$ This tool takes into account concomitant asthma diagnosis, degree of reversibility of airflow limitation, history of exacerbations and blood eosinophil count (B-Eos). The aim of the present study was to evaluate the appropriateness to ICS treatment in COPD patients from primary and secondary care in Sweden using the IPCRG tool ${ }^{9}$ and to identify factors associated with ICS treatment.

\section{Patients And Methods Data Source And Collection}

This study is part of an observational multicentre study, Tools for Identifying Exacerbations (TIE) which aims to identify factors predictive of exacerbations in COPD. ${ }^{10}$ The study population consisted of primary and secondary care patients diagnosed with COPD (ICD codes J44.0, J44.1, J44.8, J44.9) and living in mid-Sweden. The inclusion criteria were a spirometry-verified COPD diagnosis, age $\geq 40$ years, and ability to answer the questionnaires and to participate in the functional tests. Patients with a history of severe comorbidity, eg, metastasized cancer, severe heart failure, severe angina pectoris, which was clinically assessed at the inclusion visit, were excluded.
The 561 COPD patients included in this analysis all had complete data of comorbidity of asthma, history of exacerbations and B-Eos count to facilitate categorization using the IPCRG algorithm. Inclusion and exclusion criteria in the TIE study can be found elsewhere. ${ }^{10}$ Data were collected between September 2014 and September 2016 by research nurses through questionnaires at inclusion visits and retrospectively from patient records. The study was conducted in accordance with the Declaration of Helsinki and approved by the Regional Review Board in Uppsala, Sweden (Dnr2013/358). Written informed consent was obtained from all patients prior to their entering the study.

\section{Patient Characteristics And Measures}

A current list of each patient's maintenance and as-needed medications was obtained through a medication reconciliation, where a medication list that the patient brought to the study visit and the medication list in the electronic patient records were reviewed for accuracy by the research nurse and the patient jointly. The following bronchodilators and antiinflammatory drugs were recorded: short-acting beta-2-agonists (SABAs; ATC codes R03AC02, R03AC03), short-acting muscarinic antagonists (SAMAs; R03BB01), SABA + SAMA (R03AL02), long-acting beta-2-agonists (LABAs; R03AC12, R03AC13, R03AC18, R03AC19), long-acting muscarinic antagonists (LAMAs; R03BB04, R03BB05, R03BB06, R03BB07), fixed LABA/LAMA combinations (R03AL03, R03AL04, R03AL05, R03AL06), inhaled corticosteroids (ICS; R03BA), fixed ICS/LABA combinations (R03AK) and phosphodiesterase-4 inhibitor (PDE-4I; R03DX07). Height and weight were registered for calculation of body mass index (BMI). Patients were considered underweight at BMI $<22 \mathrm{~kg} / \mathrm{m}^{2}$, normal weight at BMI $22-30 \mathrm{~kg} /$ $\mathrm{m}^{2}$ and obese at BMI $>30 \mathrm{~kg} / \mathrm{m}^{2}$, as proposed by Guo et al, ${ }^{11}$ with a modified cut-off for the underweight group as recommended in the national guidelines for patients with COPD in Sweden. ${ }^{12}$ Blood samples for B-Eos were taken and analyzed (Cell-Dyn 4000; Abbott Laboratories, Abbott Park, IL, USA, and Sysmex XN-10; Sysmex America, Inc., Lincolnshire, IL, USA). B-Eos levels $\leq 400$ and $>400$ cells $/ \mu \mathrm{L}$ were classified as low and elevated, ${ }^{9}$ respectively.

Post-bronchodilator spirometry (400 $\mu \mathrm{g}$ salbutamol) without pre-test (Spiro Perfect Spirometer from Welch Allyn, Skaneateles Falls, NY, USA or Jaeger MasterScreen PFT from Erich Jaeger $\mathrm{GmbH}$, Würzburg, Germany) was performed to confirm the diagnosis of COPD as a post-bronchodilator ratio of the forced expiratory volume in 1 second $\left(\mathrm{FEV}_{1}\right)$ /forced vital capacity $<0.7$ and to measure the lung 
function, ie, $\mathrm{FEV}_{1} \%$ of predicted based on Swedish reference values. ${ }^{13,14}$ The severity of lung function impairment based on post-bronchodilator $\mathrm{FEV}_{1}$ was assessed using the GOLD classification: mild $\left(\mathrm{FEV}_{1} \geq 80 \%\right.$ of predicted), moderate $(50 \% \leq$ $\mathrm{FEV}_{1}<80 \%$ of predicted), severe $\left(30 \% \leq \mathrm{FEV}_{1}<50 \%\right.$ of predicted), very severe $\left(\mathrm{FEV}_{1}<30 \%\right.$ of predicted $) .{ }^{15}$ Demographics, smoking status, comorbidity of asthma, ie, current asthma diagnosis or history of asthma, and symptoms related to COPD were collected through a questionnaire that was sent to the patients prior to the study visits. The questionnaire was reviewed by a research nurse at the study visit and completed by the patient with assistance from the nurse if required. Symptoms were assessed using the COPD Assessment Test (CAT) ${ }^{16}$ and the modified Medical Research Council (mMRC) dyspnoea scale. ${ }^{17,18}$ The cut-off scores for a high level of symptoms for CAT and mMRC were $\geq 10$ and $\geq 2,{ }^{1}$ respectively. Each patient's history of exacerbations and information about the level of care during the year prior to study inclusion was retrospectively assessed using electronic patient records. Exacerbations were defined as acute treatment with short-acting bronchodilators by health care professionals in primary care and/or treatment with antibiotics and/or oral corticosteroids or admittance at the emergency room (ER) or hospitalization due to worsening of $\mathrm{COPD}^{19}$ Exacerbations occurring within 14 days of each other were seen as a single event. Patients with $\geq 2$ exacerbations treated in primary care or at the ER and/or $\geq 1$ hospital admission were classified as having frequent exacerbations. ${ }^{1}$ The electronic patient records in secondary care were reviewed for health care contacts. If a patient had visited the respiratory clinic due to COPD during the year before the study entry, and if the care contact was continued, this patient was classified as having a secondary health care contact. Otherwise, the patient was considered as belonging to primary care.

\section{Analysis Of Pharmacological Treatment}

The patients were divided into one of the following groups based on their COPD treatment, regardless of whether the treatment was taken through a fixed-dose inhalers or through separate inhalers: no treatment, as-needed therapy only, LABA only, LAMA only, LABA+LAMA, ICS only, ICS+LABA, ICS+LAMA, ICS+LABA+LAMA (triple therapy). Only two patients were on maintenance treatment with SABA, and these were placed in the LABA only group. To evaluate the appropriateness of the ICS therapy the COPD patients were categorized in subgroups with respect to comorbidity of asthma, history of exacerbations and B-Eos count (Figure 2). This categorization was based on recommendations from the
IPCRG. ${ }^{9}$ Degree of reversibility of airflow limitation was not included in the spirometry measurements and thus not used in the categorization. Four subgroups were identified: "appropriate treatment with ICS", "possible indication for ICS", "possible overtreatment with ICS" and "appropriate treatment without ICS". Patients with asthma on ICS treatment, and patients without asthma on ICS treatment but with frequent exacerbations and elevated B-Eos were assessed as being in the group "appropriate treatment with ICS". Patients with asthma but lacking ICS treatment, and patients without asthma or ICS treatment but with frequent exacerbations and elevated B-Eos were placed in the group "possible indication for ICS". Patients without asthma on ICS treatment with frequent exacerbations and low B-Eos levels, and patients without asthma on ICS without frequent exacerbations irrespective of B-Eos levels were categorized into the group "possible overtreatment with ICS". Patients without asthma and ICS treatment with frequent exacerbations and low B-Eos levels, and patients without asthma and ICS treatment without frequent exacerbations irrespective of B-Eos levels were assessed as belonging to the group "appropriate treatment without ICS". In a secondary analysis, we recalculated this categorization after changing the level for low B-Eos from $\leq 400$ cells $/ \mu \mathrm{L}$ as used in the IPCRG tool, to a lower cut-off value of $<300$ cells $/ \mu \mathrm{L}$ as recommended by the GOLD when starting an initial pharmacological treatment with ICS. ${ }^{20}$ According to the IPCRG tool, the patients in the groups "appropriate treatment with ICS" and "possible indication for ICS" would benefit of being treated with ICS, and the patients in the groups "appropriate treatment without ICS" and "possible overtreatment with ICS" would not benefit from being treated with ICS.

\section{Statistical Analysis}

Baseline characteristics, clinical variables, and pharmacological treatment were reported as frequencies and percentages for categorical variables and as means and standard deviations (SD) for continuous variables. There were missing data regarding smoking $(n=1)$ and $B M I(n=3)$. No values were imputed; hence patients were excluded from analyses for which they had missing values. To analyse differences in patient characteristics (sex, age, BMI, smoking status, $\mathrm{FEV}_{1} \%$ predicted, severity of airflow limitation, CAT, mMRC, level of care and study centre) between subgroups that would and would not benefit from ICS treatment, Fisher's exact test and the Mann-Whitney- $U$ test were used for categorical variables and for continuous variables, respectively. Differences in comorbidity of asthma, history of exacerbations, and B-Eos counts were not analyzed between the groups 
as they were included in the IPCRG algorithm. Variables associated with the odds of being treated with ICS in combination with LABA and/or LAMA compared with other or no therapy were identified using simple (unadjusted) and multivariable (adjusted) logistic regression analysis. Unadjusted analyses were performed for the following potential factors: sex, age, BMI, smoking status, lung function, CAT score, mMRC score, B-Eos count, comorbidity of asthma, history of exacerbations, level of care and study centre (Supplementary Figure 1). Factors shown as statistically significant were then included in a multivariate model, in order to evaluate the independent effects of the factors. Two-sided tests were applied and a $\mathrm{p}$ value $<0.05$ was considered statistically significant. Data management and statistical analyses were performed using R, version 3.4.3 ( $\mathrm{R}$ Core Team, R Foundation for Statistical Computing, Vienna, Austria, 2017).

\section{Results}

\section{Patient Characteristics}

Demographics and study characteristics for the whole study population and for the COPD treatment groups are presented in Supplementary Table 1. Of the included patients, 327 $(58 \%)$ were women, and the mean age $\pm \mathrm{SD}$ was $69 \pm 8$ years. The prevalence of underweight (body mass index $\left.(\mathrm{BMI})<22 \mathrm{~kg} / \mathrm{m}_{2}\right)$ and obese $\left(\mathrm{BMI}>30 \mathrm{~kg} / \mathrm{m}^{2}\right)$ patients was $15 \%$ and $23 \%$, respectively. A majority of the patients had a history of smoking, being either ex-smokers $(69 \%)$ or current smokers $(29 \%)$. The prevalence of patients with high levels of B-Eos ( $>400$ cells $/ \mu \mathrm{L})$ was $7 \%$ and just over a third reported comorbidity of asthma. The percentage of the COPD patients with high levels of symptoms, measured using COPD Assessment Test (CAT) and modified Medical Research Council (mMRC), was $62 \%$ and $44 \%$, respectively. One hundred seven (19\%) patients had suffered from frequent exacerbations during the year before study entry, of which 39 patients had been admitted to the hospital ward at least once. The prevalence of having a secondary care contact was $15 \%$, and $85 \%$ were treated in primary care.

\section{COPD Treatment}

The proportions of patients in each of the COPD treatment groups are presented in Figure 1A. Triple therapy, ie, ICS

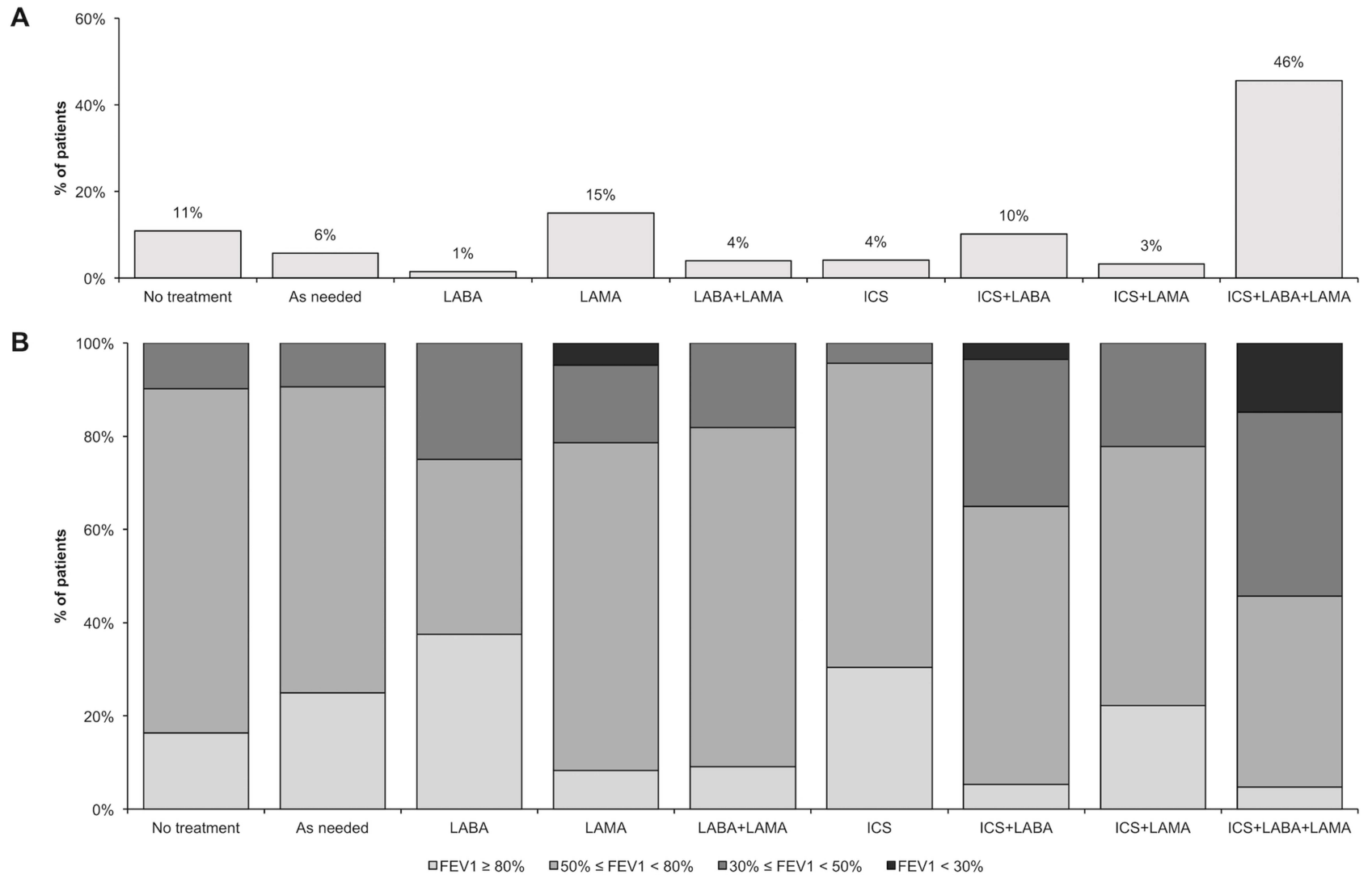

Figure I (A) COPD treatment as percentages of patients in the different COPD treatment groups for all study patients $(n=56 \mathrm{I})$. (B) Percentages of patients by severity of airflow limitation and by COPD treatment for all study patients $(n=56 \mathrm{I})$.

Abbreviations: $\mathrm{FEV}_{1}$, forced expiratory volume in I second; ICS, inhaled corticosteroid; LABA, long-acting beta-2-agonist; LAMA, long-acting muscarinic antagonist. 
in combination with LABA and LAMA, was the most frequently used treatment, followed by treatment with LAMA only and ICS in combination with LABA. The prevalence of patients with no pharmacological COPD treatment was $11 \%$, and $6 \%$ had treatment only as-needed. Seven patients were on treatment with the PDE-4 inhibitor roflumilast, six in combination with triple therapy and one in combination with as-needed COPD therapy. Of these, four were categorized in the group "Overtreatment with ICS", two and one in the groups "Appropriate therapy with ICS" and "Appropriate therapy without ICS", respectively (data not shown). Percentages of the patients by severity of airflow limitation and by COPD treatment groups are presented in Figure 1B. The numbers (\%) of patients with mild, moderate, severe and very severe lung function impairment were 56 (10\%), 308 (55\%), $153(27 \%)$ and $44(8 \%)$, respectively. Patients with mild to severe airflow limitation $\left(\mathrm{FEV}_{1} \geq 30 \%\right.$ predicted) were present in all of the treatment groups. Those with very severe airflow limitation $\left(\mathrm{FEV}_{1}<30 \%\right.$ predicted) were treated either with
LAMA as monotherapy, with LABA in combination with ICS or with triple therapy.

\section{Evaluation Of Appropriateness Of ICS Treatment}

The distribution of patients in the subgroups, with respect to comorbidity of asthma, history of exacerbations, B-Eos count and treatment with ICS was $159(28 \%), 37$ (7\%), $170(30 \%)$ and $195(35 \%)$ patients in the groups "appropriate treatment with ICS", "possible indication for ICS", "appropriate treatment without ICS" and "possible over treatment with ICS", respectively (Figure 2). Twenty percent of the patients with comorbidity of asthma lacked treatment with ICS. Of the patients with no comorbidity of asthma, all with frequent exacerbations in combination with high B-Eos levels were treated with ICS, $95 \%$ of the patients with frequent exacerbations in combination with lower B-Eos levels were treated with ICS, and $46 \%$ of the patients with no frequent exacerbations were on ICS treatment. In the secondary analysis with a lower B-Eos cut-off threshold of $\geq 300 \mu \mathrm{L} / \mathrm{mL}, 149$ (27\%) patients

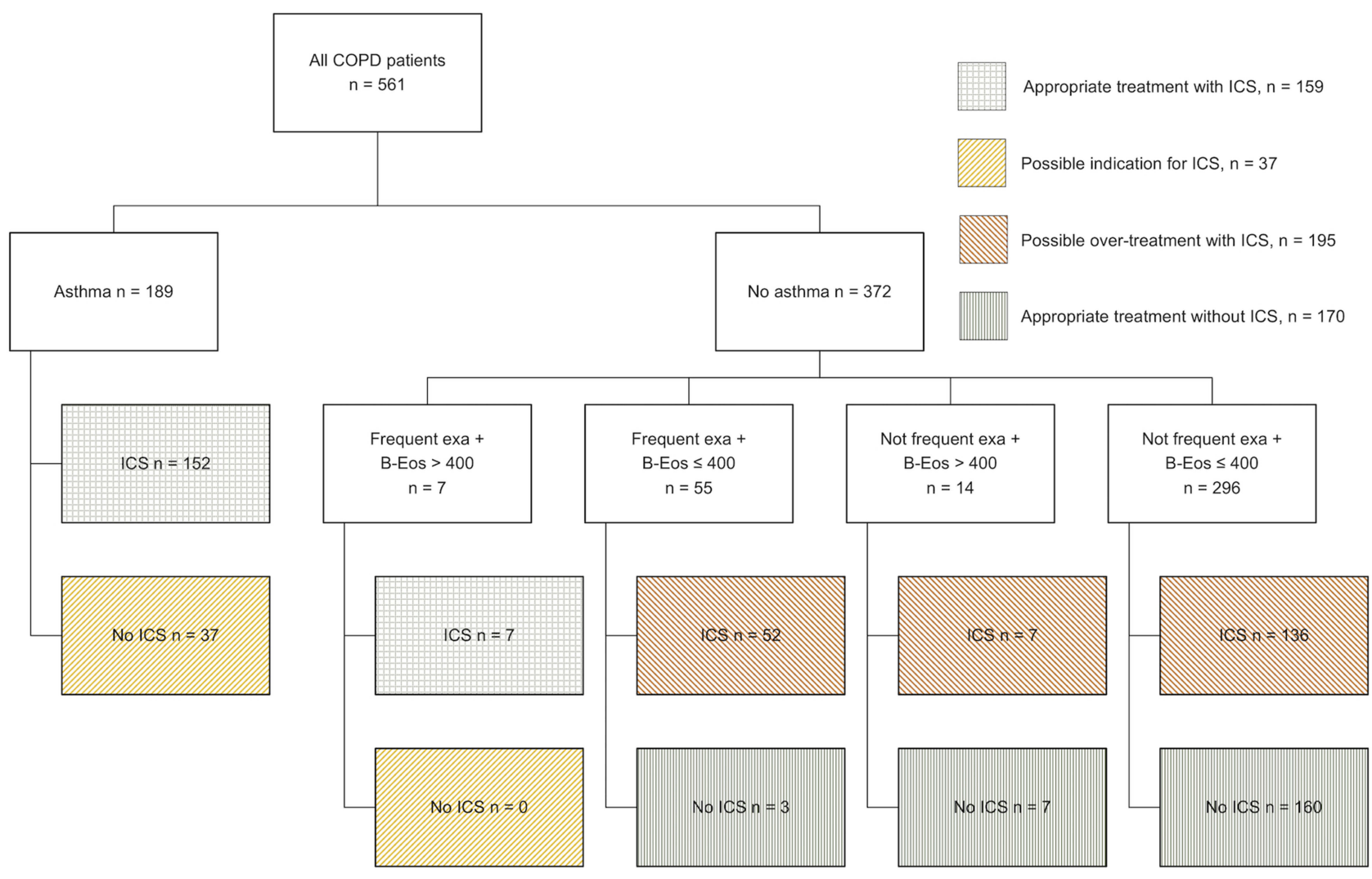

Figure 2 Flow chart of categorizing the COPD patients $(n=56 I)$ into subgroups based on comorbidity of asthma, history of exacerbations, B-Eos count and treatment of ICS.

Abbreviations: Frequent exa, frequent exacerbations, $\geq 2$ exacerbations treated in primary care or at emergency room and/or $\geq 1$ hospital admissions during the previous year due to worsening in COPD; B-Eos, blood eosinophil count as cells/ $\mu \mathrm{L}$; ICS, inhaled corticosteroid. 
Table I Characteristics Of The COPD Patients Divided In The Subgroups With Respect To Benefit And Appropriateness Of ICS Therapy In COPD

\begin{tabular}{|c|c|c|c|c|c|c|c|}
\hline & & \multicolumn{3}{|l|}{ Would Benefit of ICS } & \multicolumn{3}{|l|}{ Would Not Benefit Of ICS } \\
\hline & & $\begin{array}{l}\text { Appropriate Therapy } \\
\text { With ICS }(n=159)\end{array}$ & $\begin{array}{l}\text { Possible Indication } \\
\text { For ICS }(n=37)\end{array}$ & pValue & $\begin{array}{l}\text { Appropriate Treatment } \\
\text { Without ICS }(n=170)\end{array}$ & $\begin{array}{l}\text { Possible } \\
\text { Overtreatment With } \\
\text { ICS }(n=195)\end{array}$ & pValue \\
\hline Sex & Female & $102(64 \%)$ & $21(57 \%)$ & 0.452 & $86(51 \%)$ & 118 (61\%) & 0.058 \\
\hline \multicolumn{2}{|l|}{ Age, years } & $68(8)$ & $67(9)$ & 0.370 & $69(7)$ & $69(8)$ & 0.370 \\
\hline BMI & $\begin{array}{l}<22 \\
22-30 \\
>30\end{array}$ & $\begin{array}{l}17(11 \%) \\
93(59 \%) \\
48(30 \%)\end{array}$ & $\begin{array}{l}4(11 \%) \\
26(70 \%) \\
7(19 \%)\end{array}$ & 0.382 & $\begin{array}{l}24(14 \%) \\
106(62 \%) \\
40(24 \%)\end{array}$ & $\begin{array}{l}37(19 \%) \\
121(63 \%) \\
35(18 \%)\end{array}$ & 0.264 \\
\hline Smoking & $\begin{array}{l}\text { Never } \\
\text { Former } \\
\text { Current }\end{array}$ & $\begin{array}{l}2(1 \%) \\
114(72 \%) \\
42(27 \%)\end{array}$ & $\begin{array}{l}0(0 \%) \\
24(65 \%) \\
13(35 \%)\end{array}$ & 0.553 & $\begin{array}{l}2(1 \%) \\
105(62 \%) \\
63(37 \%)\end{array}$ & $\begin{array}{l}5(3 \%) \\
146(75 \%) \\
44(23 \%)\end{array}$ & 0.006 \\
\hline \multicolumn{2}{|c|}{$\mathrm{FEV}, \%$ predicted } & $53(17)$ & $66(16)$ & $<0.001$ & $64(15)$ & $51(18)$ & $<0.001$ \\
\hline $\begin{array}{l}\text { Severity of } \\
\text { airflow } \\
\text { limitation }\end{array}$ & $\begin{array}{l}\mathrm{FEV}_{1} \geq 80 \% \\
50 \% \leq \mathrm{FEV}_{1}<80 \% \\
30 \% \leq \mathrm{FEV}_{1}<50 \% \\
\mathrm{FEV}_{1}<30 \%\end{array}$ & $\begin{array}{l}11(7 \%) \\
80(50 \%) \\
54(34 \%) \\
14(9 \%)\end{array}$ & $\begin{array}{l}6(16 \%) \\
24(65 \%) \\
6(16 \%) \\
1(3 \%)\end{array}$ & 0.030 & $\begin{array}{l}24(14 \%) \\
120(71 \%) \\
23(14 \%) \\
3(2 \%)\end{array}$ & $\begin{array}{l}15(8 \%) \\
84(43 \%) \\
70(36 \%) \\
26(13 \%)\end{array}$ & $<0.001$ \\
\hline CAT & $\begin{array}{l}<10 \\
\geq 10\end{array}$ & $\begin{array}{l}52(33 \%) \\
107(67 \%)\end{array}$ & $\begin{array}{l}18(49 \%) \\
19(51 \%)\end{array}$ & 0.086 & $\begin{array}{l}85(50 \%) \\
85(50 \%)\end{array}$ & $\begin{array}{l}60(31 \%) \\
135(69 \%)\end{array}$ & $<0.001$ \\
\hline $\mathrm{mMRC}$ & $\begin{array}{l}<2 \\
\geq 2\end{array}$ & $\begin{array}{l}78(49 \%) \\
81(51 \%)\end{array}$ & $\begin{array}{l}22(60 \%) \\
15(40 \%)\end{array}$ & 0.278 & $\begin{array}{l}|2|(7 \mid \%) \\
49 \text { (29\%) }\end{array}$ & $\begin{array}{l}93(48 \%) \\
102(52 \%)\end{array}$ & $<0.001$ \\
\hline Level of care & $\begin{array}{l}\text { Primary } \\
\text { Secondary }\end{array}$ & $\begin{array}{l}126(79 \%) \\
33(21 \%)\end{array}$ & $\begin{array}{l}35(95 \%) \\
2(5 \%)\end{array}$ & 0.031 & $\begin{array}{l}168(99 \%) \\
2(1 \%)\end{array}$ & $\begin{array}{l}150(77 \%) \\
45(23 \%)\end{array}$ & $<0.001$ \\
\hline Study centre & $\begin{array}{l}\text { Uppsala } \\
\text { Gävleborg } \\
\text { Dalarna }\end{array}$ & $\begin{array}{l}4 \mathrm{I}(26 \%) \\
76(48 \%) \\
42(26 \%)\end{array}$ & $\begin{array}{l}9(24 \%) \\
15(41 \%) \\
13(35 \%)\end{array}$ & 0.550 & $\begin{array}{l}39(23 \%) \\
48(28 \%) \\
83(49 \%)\end{array}$ & $\begin{array}{l}58(30 \%) \\
81(42 \%) \\
56(29 \%)\end{array}$ & $<0.001$ \\
\hline
\end{tabular}

Notes: Categorical values given as $\mathrm{n}(\%)$, continuous variables given as mean (SD).

Abbreviations: BMI, body mass index; CAT, COPD Assessment Test; FEV, forced expiratory volume; ICS, inhaled corticosteroid; mMRC, modified Medical Research Council; SD, standard deviation.

were identified as having high B-Eos levels and 13 patients were moved from the group "possible over treatment" to the group "appropriate treatment with ICS" (data not shown).

The characteristics of the patients divided into the subgroups with respect to possible benefits of ICS treatment are presented in Table 1. There were significant differences in lung function and level of care when comparing the groups "appropriate therapy with ICS" and "possible indication for ICS". There were differences in smoking status, lung function, symptoms, care and study centre when comparing the groups "appropriate treatment without ICS" and "possible overtreatment with ICS".

\section{Factors Associated With ICS Treatment}

Factors associated with ICS treatment are presented in Figure 3 for the 331 patients treated with ICS in combination with LABA and/or LAMA. Statistically significant factors associated with COPD treatment including ICS in a simple logistic regression analysis were female sex, former smoking, moderate, severe or very severe lung function impairment, high CAT score, high mMRC score, comorbidity of asthma, frequent exacerbations, prevalence of secondary care contacts and study centre (Supplementary

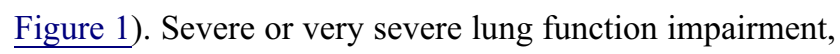
comorbidity of asthma, frequent exacerbations, and prevalence of secondary care contacts were statistically significant independent factors for COPD treatment including ICS in combination with LABA and/or LAMA in a multivariable logistic regression analysis (Figure 3 ). The results presented in Figure 3 were consistent also when adding the patients on monotherapy with ICS $(n=23)$, ie, when the outcome was changed to having ICS treatment as 


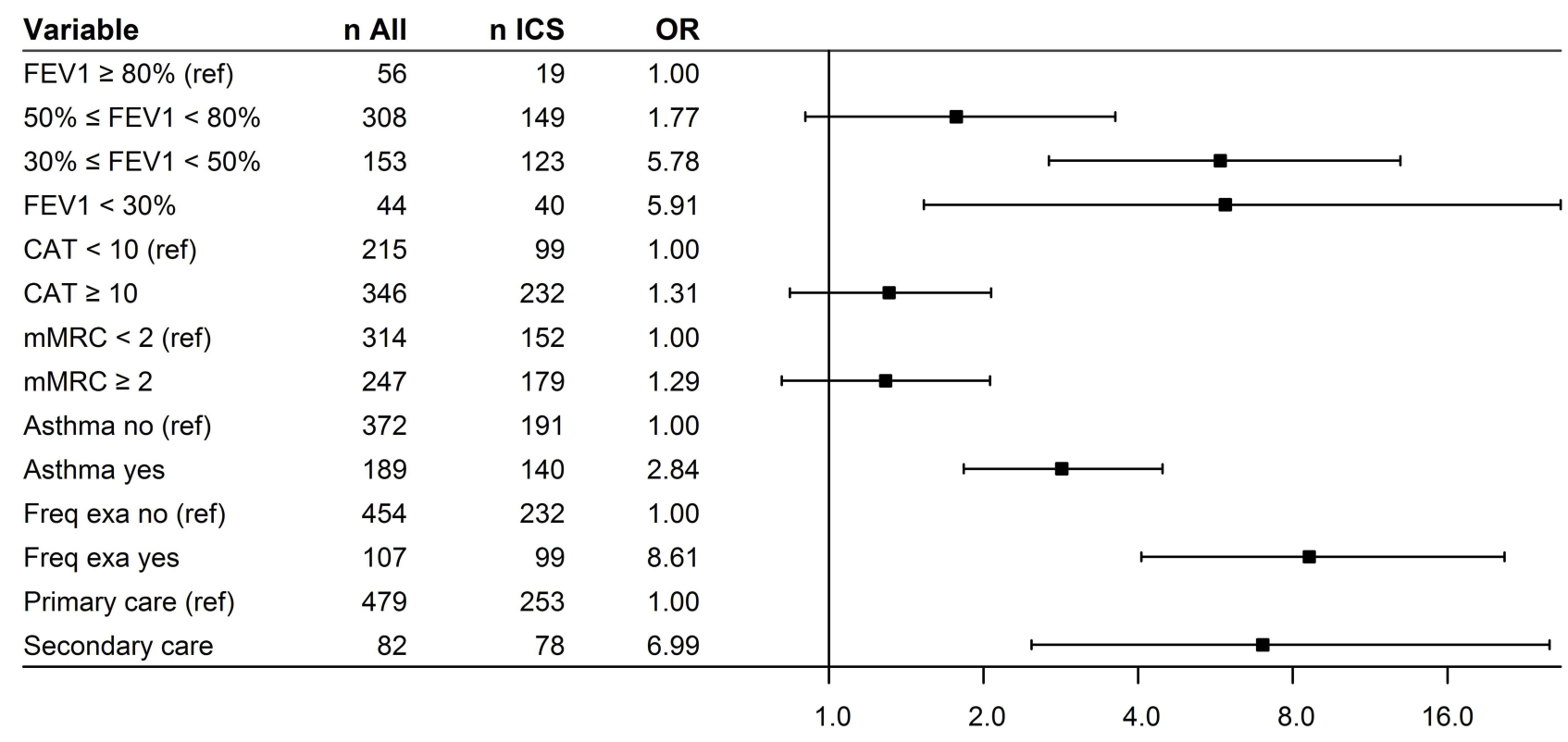

Figure 3 Adjusted odds ratios with 95\% Cls for variables associated with COPD treatment including ICS in combination with LABA and/or LAMA in a multivariable logistic regression analysis, adjusted for sex, study centre and smoking.

Abbreviations: CAT, COPD Assessment Test; $\mathrm{Cl}$, confidence interval; COPD, chronic obstructive pulmonary disease; $\mathrm{FEV}_{1}$, forced expiratory volume in I second; Freq exa, frequent exacerbations, $\geq 2$ exacerbations treated in primary care or at emergency room and/or $\geq 1$ hospital admissions during the previous year due to worsening in COPD; ICS, inhaled corticosteroid; LABA, long-acting beta-2-agonist; LAMA, long-acting muscarinic antagonist; mMRC, modified Medical Research Council; OR, odds ratio; ref, reference.

monotherapy or in combination with bronchodilators (data not shown).

\section{Discussion}

In this observational multicentre study in COPD patients from Swedish primary and secondary care, almost two-thirds of the patients were treated with ICS only or in combination with other drugs. Triple treatment was found to be the most common treatment combination, used by almost half of the patients. The prevalence of triple treatment was slightly higher compared within an earlier study in Sweden (46\% vs $40 \%){ }^{6}$ We also found patients for whom there was an indication for starting an ICS treatment and others who had an inappropriate treatment in terms of ICS as monotherapy or ICS in combination with LAMA without LABA. This is the first study, to our knowledge, that has studied the appropriateness to ICS treatment in COPD using the IPCRG algorithm ${ }^{9}$ which includes comorbidity of asthma, exacerbation frequency, and B-Eos count. The majority of the COPD patients who were not appropriately treated with ICS were classified as possibly over-treated in our study, including patients without comorbidity of asthma who were not experiencing frequent exacerbations in combination with high B-Eos levels.

B-Eos count has been suggested as a biomarker for estimating the efficacy of ICS in prevention of exacerbations ${ }^{20}$ as there appears to be a relationship between B-Eos and ICS effects. ${ }^{21-24}$ However, at the time of the data collection in 2014-2016, B-Eos count was not used when evaluating the pharmacological treatment in COPD and was not mentioned in national guidelines. ${ }^{25}$ A majority of the patients (95\%) without asthma but with frequent exacerbations in combination with low levels of B-Eos were treated with ICS and, thus they were categorized as "possible over treated with ICS" according to the IPCRG tool. This is in contrast to both national and GOLD guidelines, suggesting ICS as a treatment option for patients with frequent exacerbations. This is also evident from the lack of association between B-Eos and ICS including COPD treatment (Supplementary Figure 1). The IPCRG is suggesting that patients with B-Eos count of $>400$ cells $/ \mu \mathrm{L}$ would benefit from being treated with ICS. ${ }^{9}$ However, according to the GOLD ${ }^{2019,20}$ a lower B-Eos cutoff level of $\geq 300$ cells $/ \mu \mathrm{L}$ is recommended, as these patients have been shown to have the most exacerbation-reducing effect when treated with ICS. ${ }^{24,26}$ In our study, lowering the threshold of B-Eos to $\geq 300$ cells $/ \mu \mathrm{L}$ led to only a minor change in the percentage of patients classified as "possible over treatment with ICS", which decreased from $35 \%$ to $32 \%$.

The Swedish national guidelines for COPD treatment were updated on October 2015. In the older guidelines, the 
recommendations of pharmacological therapy were solely based on the spirometric assessment of airflow limitation and ICS was recommended as exacerbation prophylaxis for patients with $\mathrm{FEV}_{1}<50 \%$ of predicted value and recurrent exacerbations. ${ }^{27}$ In our study, almost half of the patients in the group "possible overtreatment with ICS" had severe or very severe lung function impairment, ie, $\mathrm{FEV}_{1}<50 \%$ of predicted value. After the national guideline update, the pharmacological treatment in COPD was suggested to be based on the combined COPD assessment, as recommended by the international GOLD $^{2014,25,28}$ which includes a history of exacerbations and symptomatic assessment of COPD. ICS in combination with LABA was recommended for patients with frequent exacerbations and significant symptoms despite earlier treatment with long-acting bronchodilators and as an alternative to bronchodilators for patients with a high symptom burden in combination with an $\mathrm{FEV}_{1}<50 \%$ of the predicted value. According to GOLD, ICS is not the recommended treatment for COPD in patients without comorbidity of asthma and/or frequent exacerbations. ${ }^{1}$ In our study, $46 \%$ of the patients with no history of frequent exacerbations and no comorbidity of asthma were treated with ICS-containing therapy, a number slightly lower than in other studies in similar patients. ${ }^{5,7,29}$ Chalmers et al reported that $56 \%$ of the GOLD A and B patients without concomitant asthma were using ICS in a study in the UK. ${ }^{5}$ Thomas et al described that $69 \%$ of the COPD patients without asthma and frequent exacerbations were treated with ICS. ${ }^{29}$ However, the definition for frequent exacerbations was $\geq 3$ exacerbations during the preceding year, ${ }^{29}$ which is different from the cut-off that GOLD use for frequent exacerbations. ${ }^{1,29}$ Also, Casas et al found that $50 \%$ of the GOLD A and B group patients were using ICS in combination with LABA or as triple treatment. ${ }^{7}$

Our finding that one-fifth of the COPD patients with possible indication for ICS treatment, ie, patients with comorbidity of asthma, were not receiving ICS treatment, is similar to what was seen in a study in the $\mathrm{UK}^{29}$ showing that $18 \%$ of the COPD patients with a concomitant asthma diagnosis were not treated with ICS.

As expected, severe and very severe airflow limitation, comorbidity of asthma, frequent exacerbations, and contact with secondary care were associated with ICS-containing therapy, and this is also supported by other studies. $^{5,30}$ Among the patients who would benefit from ICS treatment (Table 1), the patients with "possible indication for ICS" had a better lung function when compared with the patients with "appropriate therapy with ICS", which might be a reason why they did not have ICS treatment despite reported comorbidity of asthma. Larger differences were observed between the two groups of patients who would not benefit from ICS according to the IPCRG tool, ie, when comparing "appropriate treatment without ICS" and "possible overtreatment with ICS". Patients with "possible overtreatment with ICS" were shown to have lower lung function and more symptoms which might explain why they were being treated with ICS.

The major strength of this study is that it is a multicentre real-world study with COPD patients from both primary and secondary health care settings. Further, information about patients' pharmacological treatments was obtained through medication reconciliations, ie, through face-toface interviews. In other observational cross-sectional studies in COPD patients, the sources of medication information have been prescription records, ${ }^{7}$ patient records ${ }^{5,29}$ and questionnaires mailed to patients. ${ }^{6}$ This study also has some limitations. One limitation is that the IPCRG algorithm is not validated and the validity of this study is depending on the quality of the data used in the IPCRG algorithm. We might have overestimated the proportion of patients with asthma as the information was self-reported by the patients. Another possible limitation in this study is that there was no reversibility testing of airflow limitation performed as a part of the spirometry, which is recommended as an alternative in the IPCRG tool when diagnosing patients with a comorbidity of asthma. Further, even though B-Eos has been identified as a promising biomarker for the identification of an increased risk for exacerbations in COPD patients, there are also concerns about high variabilities and treatment dependencies. ${ }^{2,26,31}$ In summary, even though the IPCRG tool provides guidance to ICS withdrawal, the information today is still limited about the outcome of withdrawal of ICS, and clinical studies addressing this are urgently needed.

\section{Conclusion}

More than half of the COPD patients on ICS met the criteria where withdrawal of the treatment could be tried. There was, however, also a subgroup of patients not using ICS for whom there was an indication for starting ICS treatment. Patients using ICS were characterized by more frequent exacerbations and lower lung function. A national plan would be needed to implement the new guidelines in 
order to increase the knowledge among prescribers about which COPD patients benefit of using ICS.

\section{Data Availability}

Data cannot be made freely available as they are subject to secrecy in accordance with the Swedish Public Access to Information and Secrecy Act, but can be made available to researchers upon request (subject to a review of secrecy).

\section{Acknowledgments}

The authors thank the personnel at the Dalarna, Gävleborg and Uppsala research units and statistician Sara Gustavsson for the support and guidance in statistics and Linnéa Holmén for proofreading the manuscript. This study was funded by the Uppsala-Örebro Regional Research Council, the Centre for Research \& Development, Uppsala University/Region Gävleborg, the Centre for Clinical Research, Uppsala University, County Council Dalarna, the Swedish Heart-Lung Foundation, the Swedish Heart and Lung Association and the Bror Hjerpstedt Foundation.

\section{Author Contributions}

$\mathrm{MH}, \mathrm{CJ}, \mathrm{AM}, \mathrm{BS}, \mathrm{KB}, \mathrm{KL}$ and JS initiated and designed the TIE study. JS, CJ, HM, MHU and EIN contributed to the data analysis performed in this manuscript. JS had full access to the study data and takes full responsibility for the integrity of the data and the accuracy of the analysis, and wrote the first draft of the manuscript. All authors analyzed and interpreted the data, contributed with critical revision of the manuscript, approved the final version to be published, and agree to be accountable for all aspects of the work.

\section{Disclosure}

JS has received a payment for an educational activity from Orion Pharma. CJ has received payments for educational activities from AstraZeneca, Boehringer Ingelheim, Chiesi, Novartis and TEVA, and has served on advisory boards organized by AstraZeneca, Boehringer Ingelheim, Chiesi, GlaxoSmithKline, Novartis and TEVA. BS has received honoraria for educational activities and lectures from AstraZeneca, Boehringer Ingelheim, GlaxoSmithKline, Novartis, Meda and TEVA and has served on advisory boards organized by AstraZeneca, Novartis, GSK, Boehringer Ingelheim, TEVA and Meda. KL has received honoraria for educational activities and lectures from AstraZeneca, Novartis, TEVA, Chiesi and
GlaxoSmithKline and has served on advisory boards organized by Novartis and Boehringer Ingelheim. No potential conflicts of interests were reported by any of the other authors.

\section{References}

1. Vogelmeier CF, Criner GJ, Martinez FJ, et al. Global strategy for the diagnosis, management, and prevention of chronic obstructive lung disease 2017 report. GOLD executive summary. Am J Respir Crit Care Med. 2017;195(5):557-582. doi:10.1164/rccm.201701-0218PP

2. Wedzicha JA, Banerji D, Chapman KR, et al. Indacaterol-glycopyrronium versus salmeterol-fluticasone for COPD. $N$ Engl J Med. 2016;374(23):2222-2234. doi:10.1056/NEJMoa1516385

3. Magnussen H, Disse B, Rodriguez-Roisin R, et al. Withdrawal of inhaled glucocorticoids and exacerbations of COPD. $N$ Engl J Med. 2014;371(14):1285-1294. doi:10.1056/NEJMoa1407154

4. Lipson DA, Barnhart F, Brealey N, et al. Once-daily single-inhaler triple versus dual therapy in patients with COPD. $N$ Engl J Med. 2018;378(18):1671-1680. doi:10.1056/NEJMoa1713901

5. Chalmers JD, Tebboth A, Gayle A, Ternouth A, Ramscar N. Determinants of initial inhaled corticosteroid use in patients with GOLD A/B COPD: a retrospective study of UK general practice. NPJ Prim Care Respir Med. 2017;27(1):43. doi:10.1038/s41533-0170040-z

6. Sundh J, Aberg J, Hasselgren M, et al. Factors influencing pharmacological treatment in COPD: a comparison of 2005 and 2014. Eur Clin Respir J. 2017;4(1). doi:10.1080/20018525.2017.1409060

7. Casas A, Montes de Oca M, Menezes AM, et al. Respiratory medication used in COPD patients from seven Latin American countries: the LASSYC study. Int J Chron Obstruct Pulmon Dis. 2018;13:15451556. doi:10.2147/COPD.S154097

8. Kaplan AG. Applying the wisdom of stepping down inhaled corticosteroids in patients with COPD: a proposed algorithm for clinical practice. Int J Chron Obstruct Pulmon Dis. 2015;10:2535-2548. doi:10.2147/COPD.S93321

9. International Primary Care Respiratory Group (IPCRG). Evaluation of appropriateness of inhaled corticosteroid (ICS) therapy in COPD and guidance on ICS withdrawal. March-July 2018. Available from: https://www.theipcrg.org/. Accessed October 17, 2019.

10. Högman M, Sulku J, Ställberg B, et al. 2017 global initiative for chronic obstructive lung disease reclassifies half of COPD subjects to lower risk group. Int J Chron Obstruct Pulmon Dis. 2018;13:165173. doi:10.2147/COPD.S151016

11. Guo Y, Zhang T, Wang Z, et al. Body mass index and mortality in chronic obstructive pulmonary disease: a dose-response meta-analysis. Medicine. 2016;95(28). doi:10.1097/MD.0000000000004225

12. The National Board of Health and Welfare (Socialstyrelsen). Nationella riktlinjer för vård vid astma och KOL. 2018 Available from: http://www.socialstyrelsen.se/. Accessed October 17, 2019.

13. Hedenstrom H, Malmberg P, Agarwal K. Reference values for lung function tests in females. Regression equations with smoking variables. Bull Eur Physiopathol Respir. 1985;21(6):551-557.

14. Hedenstrom H, Malmberg P, Fridriksson HV. Reference values for lung function tests in men: regression equations with smoking variables. Ups J Med Sci. 1986;91(3):299-310. doi:10.3109/ 03009738609178670

15. Vestbo J, Hurd SS, Agustí AG, et al. Global strategy for the diagnosis, management, and prevention of chronic obstructive pulmonary disease. Am J Respir Crit Care Med. 2013;187(4):347-365. doi:10.1164/rccm.201204-0596PP

16. Jones PW, Harding G, Berry P, Wiklund I, Chen WH, Kline Leidy N. Development and first validation of the COPD Assessment Test. Eur Respir J. 2009;34(3):648-654. doi:10.1183/09031936.00102509 
17. Wedzicha JA, Bestall JC, Garrod R, Garnham R, Paul EA, Jones PW. Randomized controlled trial of pulmonary rehabilitation in severe chronic obstructive pulmonary disease patients, stratified with the MRC dyspnoea scale. Eur Respir J. 1998;12(2):363-369. doi:10. 1183/09031936.98.12020363

18. Mahler DA, Rosiello RA, Harver A, Lentine T, McGovern JF, Daubenspeck JA. Comparison of clinical dyspnea ratings and psychophysical measurements of respiratory sensation in obstructive airway disease. Am Rev Respir Dis. 1987;135(6):1229-1233. doi:10. 1164/arrd.1987.135.6.1229

19. Rodriguez-Roisin R. Toward a consensus definition for COPD exacerbations. Chest. 2000;117(5Suppl 2):398s-401s. doi:10.1378/ chest.117.5_suppl_2.398S

20. Global Initiative for Chronic Obstructive Lung Disease (GOLD). Global strategy for the diagnosis management, and prevention of chronic obstructive pulmonary disease. 2019. Available from: https://goldcopd.org/. Accessed October 17, 2019.

21. Ismaila AS, Birk R, Shah D, et al. Once-daily triple therapy in patients with advanced COPD: healthcare resource utilization data and associated costs from the FULFIL trial. Adv Ther. 2017;34 (9):2163-2172. doi:10.1007/s12325-017-0604-x

22. Bafadhel M, Peterson S, De Blas MA, et al. Predictors of exacerbation risk and response to budesonide in patients with chronic obstructive pulmonary disease: a post-hoc analysis of three randomised trials. Lancet Respir Med. 2018;6(2):117-126. doi:10.1016/S22132600(18)30006-7

23. Papi A, Vestbo J, Fabbri L, et al. Extrafine inhaled triple therapy versus dual bronchodilator therapy in chronic obstructive pulmonary disease (TRIBUTE): a double-blind, parallel group, randomised controlled trial. Lancet. 2018. doi:10.1016/S0140-6736(18)30206-X
24. Vestbo J, Papi A, Corradi M, et al. Single inhaler extrafine triple therapy versus long-acting muscarinic antagonist therapy for chronic obstructive pulmonary disease (TRINITY): a double-blind, parallel group, randomised controlled trial. Lancet. 2017;389(10082):19191929. doi:10.1016/S0140-6736(17)30188-5

25. Swedish Medical Products Agency (Läkemedelsverket). Kroniskt obstruktiv lungsjukdom (KOL) behandlingsrekommendation. 2015. Available from: https://lakemedelsverket.se/. Accessed October 17, 2019.

26. Siddiqui SH, Guasconi A, Vestbo J, et al. Blood eosinophils: a biomarker of response to extrafine beclomethasone/formoterol in chronic obstructive pulmonary disease. Am J Respir Crit Care Med. 2015;192(4):523-525. doi:10.1164/rccm.201502-0235LE

27. Swedish Medical Products Agency (Läkemedelsverket). Farmakologisk behandling av kroniskt obstruktiv lungsjukdom - KOL. 2009. Available from: https://lakemedelsverket.se/. Accessed October 17, 2019.

28. Global Initiative for Chronic Obstructive Lung Disease (GOLD). Global strategy for the diagnosis, management and prevention of COPD. 2014. Available from: https://goldcopd.org/. Accessed October 17, 2019.

29. Thomas M, Radwan A, Stonham C, Marshall S. COPD exacerbation frequency, pharmacotherapy and resource use: an observational study in UK primary care. Copd. 2014;11(3):300-309. doi:10.3109/15 412555.2013.841671

30. Roman-Rodriguez M, van Boven JF, Vargas F, et al. Factors associated with inhaled corticosteroids prescription in primary care patients with COPD: a cross-sectional study in the Balearic Islands (Spain). Eur J Gen Pract. 2016;22(4):232-239. doi:10.1080/1381 4788.2016.1212011

31. Roche N, Chapman KR, Vogelmeier CF, et al. Blood eosinophils and response to maintenance chronic obstructive pulmonary disease treatment. data from the FLAME trial. Am J Respir Crit Care Med. 2017;195(9):1189-1197. doi:10.1164/rccm.201701-0193OC

\section{Publish your work in this journal}

The International Journal of COPD is an international, peer-reviewed journal of therapeutics and pharmacology focusing on concise rapid reporting of clinical studies and reviews in COPD. Special focus is given to the pathophysiological processes underlying the disease, intervention programs, patient focused education, and self management protocols. This journal is indexed on PubMed Central, MedLine and CAS. The manuscript management system is completely online and includes a very quick and fair peer-review system, which is all easy to use. Visit http://www.dovepress.com/testimonials.php to read real quotes from published authors. 